\title{
DAC-EuCheMS Lecture Award presented to ABC Advisory Board Member Miguel Valcárcel
}

\author{
Nicola Oberbeckmann-Winter ${ }^{1}$ (D)
}

Received: 2 September 2015 / Accepted: 4 September 2015 /Published online: 3 October 2015

(C) Springer-Verlag Berlin Heidelberg 2015

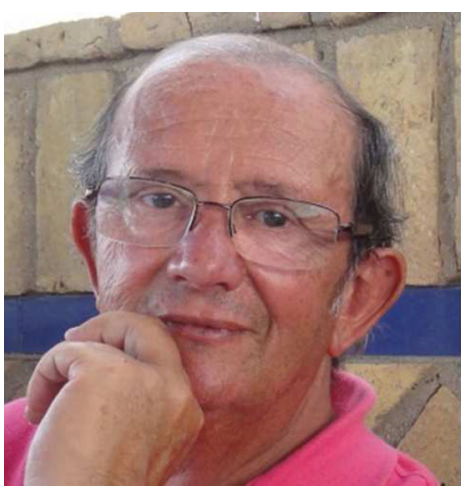

Miguel Valcárcel has been Full Professor of Analytical Chemistry at the University of Córdoba since 1976. His main research lines are analytical nanoscience and nanotechnology and automatization/miniaturization/quality of (bio)chemical measurement processes. He is the author or coauthor of more than 900 articles indexed in international databases (Hirsch index 50), nine monographs, ten textbooks, and 20 chapters in multiauthor books. He has also been the coordinator of 25 Spanish scientific research projects and 14 international scientific research projects, as well as of 12 contracts with private firms, and has promoted a spin-off company devoted to nanotechnology. He has been supervisor/co-supervisor of 75 doctoral candidates and invited lecturer at 80 international meetings. He is the recipient of numerous national scientific awards (e.g., the Solvay Prize of the Spanish Confederation of Enterprises Organization, 2000; the National Award in Chemistry, 2005; the Maimonides Award, 1993) and international awards (e.g., the Enrich Planquette Award of the Austrian Society of Chemistry, 1996; the Robert Boyle Medal of the Royal Society of Chemistry, UK, 2004; the DAC-EuChemMS Award, 2015). He has also received an honorary doctorate from the University of Valencia (2011, Spain), and has been a full member of the Spanish Royal Academy of Sciences since 2010.

Nicola Oberbeckmann-Winter

nicola.oberbeckmann-winter@springer.com

1 Tiergartenstrasse 17, 69121 Heidelberg, Germany
The DAC-EuCheMS Lecture Award, sponsored by Springer-Verlag, recognizes a European individual who has demonstrated significant and sustained achievements in research or education in analytical chemistry throughout his or her career. Miguel Valcárcel is the recipient of the 2015 DAC-EuCheMS Award. His lecture, entitled "Quo vadis, analytical chemistry," was presented at the 18th European Conference on Analytical Chemistry (Euroanalysis 2015), held in Bordeaux, France, from September 6 to September 10, 2015.

\section{Who is Miguel Valcárcel?}

Miguel Valcárcel has talked to Nicola Oberbeckmann-Winter about his research, his motivation, and himself.

\section{What is the focus of your award-winning research and what was/is your motivation}

This is a special award because it recognizes not only an achievement but also an academic and scientific career. I am very glad to be the first scientist to receive this European prize. I suppose that my dedication and commitment to promoting analytical chemistry in Europe for almost half a century is the principal argument for awarding it to me. Probably the recognition of my enthusiasm to teach our discipline in an innovative way is the facet of the award that is most relevant for me.

My motivation has always been the distorted (sometimes poor) image of analytical chemistry among other chemists and professionals and the scarce dedication of analytical chemists to change the situation, which does not agree with my own conception of our discipline. 
The distinct feature of analytical chemistry is the (bio)chemical information; this statement has been my polestar, my way, my guide, and the principal argument in my debates with other scientists, trying to place our discipline in its correct position.

\section{What is the trickiest problem you have had to overcome in that research? How did you solve it?}

The most difficult problem to achieve the full recognition of analytical chemistry as a first-class discipline of chemistry arises from the many analytical chemists who do not accept changes. Convincing them is equivalent to surpassing the activation energy of a chemical reaction. The negative opinion of other chemists who consider it as a second-class discipline because of ignorance or lack of interest is also a mountain to be climbed. In addition, the attitude of other professionals who consider that a technician can perform the tasks of analytical chemists, forgetting the relevance of research, development, and innovation in our discipline, is also a serious obstacle.

My strategies for more than 45 years have been focused, on the one hand, on changing the teaching of analytical chemistry and thus avoiding the poor, distorted first image of our discipline among students, and on the other hand, on dealing within my research with hot topics (from automation of flow injection analysis to analytical nanoscience and nanotechnology) relevant to the trends in science and technology.

\section{From where did you start and how does your current work relate to/differ from your scientific roots?}

I started in the 1970 s teaching analytical chemistry in a traditional way. Then, in the 1990s, I changed the content, rhythm, and emphasis to the principles of it in the curriculum. The new approach has been the subject of two textbooks published in the twenty-first century. I am very satisfied with the results achieved in this strategic issue.

The evolution of my research topics has been in parallel with the availability of tools and the trends in science and technology. My early work was related to chelate formation of new ligands with metallic ions for photometric determination of metal traces. Then, automation, miniaturization, and simplification were my principal goals. In the past two decades I have fully devoted my efforts to contributing to analytical nanoscience and nanotechnology.

\section{How would you explain your current research to a child?}

The use of well-known examples from real life is the best strategy to make your message understandable.

As regards a modern vision of analytical chemistry, we can use as a case study the home glucometer for in situ monitoring of glucose concentration in blood in comparison with the traditional way of extracting blood in a hospital.

As regards analytical nanoscience and nanotechnology, a case study could be experiments involving reduction of $\mathrm{Au}^{3+}$ under different conditions in such a way that a variety of colors of gold nanoparticles are obtained. This is an excellent example of the extraordinary physicochemical properties of the nanoworld.

\section{Where do you consider your field is heading?}

There are several analytical chemistry challenges. One of the most relevant is the analysis of samples far from the human macroworld (the central position of the pendulum to the extremes of it). On one side, the analysis of the nanoworld and, on the other, extraterrestrial analysis. These challenges will be achieved only by breaking down the traditional frontiers between disciplines and by the creation of new paradigms - that is, moving from knowledge to imagination, according to Einstein.

\section{Which recent discovery might prove most valuable to the field of bioanalytical research or beyond?}

The great potential of analytical nanoscience and nanotechnology in its three facets - namely (1) metallic, carbon-based, silica, etc., nanoparticles as analytical tools to improve analytical processes; (2) nanoparticles as target analytes to be characterized and determined in different matrices; and (3) involvement of both nanotools and nanoparticles in the same analytical process.

This last avenue of analytical nanoscience and nanotechnology has been recently pointed out by A.I. López-Lorente and myself. We named it the "third way of analytical nanoscience and nanotechnology."

\section{What motivated you to become a researcher?}

By chance, my first job (1968-1969) was in a research department at Bayer in Leverkusen (Germany). The exciting topic (the development of silicones), at the frontier of knowledge at 
the end of the 1960s, opened my mind, and research became the main goal in my professional career.

\section{What do you find most rewarding in your professional life?}

A combination of aspects is the most gratifying part of my professional life. First, teaching analytical chemistry in an innovative way to undergraduate, master's, and doctoral students. Second, being permanently in touch with young people; this is a treasure for university lecturers and researchers. Third, permanently looking for innovation in analytical research, trying to be at the frontier of analytical knowledge. Fourth, sharing with the colleagues in our research team the achievements in the form of prizes, awards, recognitions, etc., of national or international nature.

\section{What is your advice for young analytical scientists today?}

To work hard with enthusiasm to promote modern (new) analytical chemistry as a first-class discipline of chemistry dealing with (bio)chemical information, which is the most distinct feature of our discipline. Also it is important to be receptive to advances in science and technology as well as to be open to working in a collaborative team not as high-level technicians producing data but as scientists participating in all the steps of interdisciplinary projects.

\section{Which ABC feature do you like (best) and why?}

The bioanalytical facets (biospecies as analytes and as tools) are, no doubt, the most remarkable feature of Analytical and Bioanalytical Chemistry. The reasons are very simple. The characterization of biospecies in difficult biological samples is a great challenge, as is the exploitation of the extraordinary properties of the biological matter to be incorporated as a tool to improve analytical processes.

\section{Finally, what do you enjoy most when you have time to spare?}

Time to spare has been scarce in my life. I recognize that has been a great error. Work has been a sponge, and it is difficult to develop hobbies, like growing plants, without the minimum of humidity and time. In general, I love all types of sports, especially football (I am an enthusiastic supporter of Barcelona). I have started some hobbies, such as painting and photography of the sea. Mozart is my favorite musician, and I love both thrillers and historical novels. 